\title{
Eco-efficiency Assessment in Agriculture: A Literature Review Focused on Methods and Indicators
}

\author{
Luis H. Suzigan ${ }^{1}$, Carlos Rosano Peña ${ }^{1,2} \&$ Patricia Guarnieri ${ }^{1,2}$ \\ ${ }^{1}$ Programa de Pós-Graduação em Agronegócios, Universidade de Brasilia, Brasilia, Brazil \\ ${ }^{2}$ Faculdade de Economia, Administração, Contabilidade e Gestão de Políticas Públicas, Universidade de Brasilia, \\ Brasilia, Brazil \\ Correspondence: Luis H. Suzigan, Campus Universitário Darcy Ribeiro, ICC Sul, Sala ASS 182, Brasilia, DF, \\ Brazil. Tel: 55-61-3107-7178. E-mail: luis.suzigan@gmail.com
}

Received: April 24, 2020

doi:10.5539/jas.v12n7p118
Accepted: May 27, $2020 \quad$ Online Published: June 15, 2020

URL: https://doi.org/10.5539/jas.v12n7p118

\begin{abstract}
Combining economic performance with environmental and social concern has been a developing topic in recent decades. Eco-efficiency analysis is a widely applied tool to assess the efficiency of agricultural systems, while increasingly considering their environmental and social impact. The main objective of this article is to accomplish a literature review on the application of eco-efficiency analysis in agricultural systems, focusing on methods and indicators that are most regarded for the quantitative assessment of agricultural eco-efficiency. The literature review found two main methods most widely applied to assess eco-efficiency: Life Cycle Assessment (LCA) and Data Envelopment Analysis (DEA), which are often combined. LCA is generally focused on the assessment of the environmental impacts of products and practices. DEA is mostly used to measure the eco-efficiency of decision-making units, such as farms, regions, or countries, and has no subjective focus on neither technical nor environmental performance. Both methods share a wide range of economic and environmental indicators but fail to incorporate the social dimension of sustainability into the eco-efficiency analysis. A simple framework, based on Data Envelopment Analysis, is offered to assess the eco-efficiency of the Brazilian agriculture, aiming at identifying the benefits and limitations of the analysis.
\end{abstract}

Keywords: eco-efficiency, agriculture, data envelopment analysis (DEA)

\section{Introduction}

The environmental impact of human activities has received significant attention from interdisciplinary research in recent decades. Public entities and private businesses have been increasingly required to adopt policy and managerial choices to combine economic performance with environmental and social concern.

The concern with sustainable activities is notably present in agricultural research. Agriculture represents only $3.5 \%$ of the world's Gross Domestic Product (World Bank, 2017) but is essential for human survival and social stability. Despite irreversible urbanization trends, $45 \%$ of the world's population still lives in rural areas (United Nations Population Division, 2017); and agricultural activities employs $26 \%$ of the global labor force (International Labor Organization [ILO], 2017). Environmental impacts are also significant, once agriculture is responsible for 33\% of total GHG-greenhouse gas emissions (Intergovernmental Panel on Climate Change [IPCC], 2014).

Inputs of agricultural activities also have large environmental and social impacts. The expansion of land-use for cultivation has increased deforestation and depleted natural resources, impoverishing biodiversity. Agrochemicals such as fertilizers and pesticides are responsible for soil and groundwater contamination, inflicting health problems to rural workers and local populations. Agriculture has a significant responsibility in climate change and declining water resources, which are increasingly challenging the very sustainability of food supply and social stability (Turral et al., 2011).

Eco-efficiency analysis has been a widely applied tool to assess the performance of agricultural systems, while considering their environmental impacts. The main objective of the article is to accomplish a literature review on the application of eco-efficiency analysis in agricultural systems. The focus of the review is on methods and indicators that are most regarded for the quantitative assessment of agricultural eco-efficiency. 
The review follows the methods proposed by Pagani et al. (2015), encompassing articles published in main electronic databases from 1992 to 2018. This timespan is established once the term eco-efficiency was conceived in 1992, at the United Nations Conference on Environment and Development-Rio Earth Summit, introduced in the publication Changing Course of the World Business Council for Sustainable Development (Schmidheiny, 1992).

The specific intentions of the literature review are to: (i) select research articles in which the primary topic is eco-efficiency analysis applied to agricultural systems; (ii) identify, through quantitative bibliometric indicators, which are the main geographical, institutional and research areas of the selected articles; (iii) identify which are the main methods and indicators applied in the eco-efficiency analysis of agricultural systems, as well the object of the analysis (whether products, practices, farms, regions, countries etc.); and (iv) analyze the main purposes for which eco-efficiency analysis is applied to agricultural systems.

Through these specific objectives, this article intends to contribute to scientific research by identifying the benefits and limitations of the eco-efficiency analysis when applied to agricultural systems. Specifically, this article intends to fulfill the objective of contributing to the construction of an ecoefficiency framework which could, through future research, add to the assessment of the sustainability of agricultural systems in Brazil-a country that still has large portions of land with preserved native forests of several biomes, which have been increasingly threatened by environmentally degrading agricultural practices.

\section{Conceptual Background: From Productivity to Eco-efficiency and DEA}

The background for eco-efficiency analysis encompasses two widely examined concepts in social science research: productivity and sustainability. The former is defined within a more delimited framework and is regarded as a tool to measure the efficiency of economic activities. The latter, as well as adjacent concepts of sustainable development, comprises more diverse and less objective definitions.

Productivity is generally understood as the capability to produce the most with the least resources. According to staff research from the Organization for Economic Co-operation and Development (OECD) and from the United States Department of Agriculture (USDA), output and input indicators can be combined to offer measures of production functions of single-factor productivity, multi-factor productivity and total factor productivity (OECD, 2001; Wang et al., 2013).

Production outputs and inputs can be expressed in monetary or quantity measures. Agricultural output, for instance, can be expressed either in gross value added or in the physical weight of production. Examples of labor input indicators are wage expenses, number of employees or hours worked. Intermediate input indicators can be expressed as expenses or the physical amount employed in production, such as pesticide-use measured either in monetary costs or the weight of active ingredient. Similarly, examples of capital inputs can be machinery depreciation costs or machinery utilization (number of units or measured power).

To reach a productivity measure, one does not necessarily have to compare the numerator and the denominator in the same standard. For instance, in measuring labor productivity one can use the output indicator in monetary terms (such as sales revenue) and the input denominator in quantity terms (number of employees). The above revenue per employee indicator is an example of a single-factor productivity measure. One of the single-factor productivity measures most regarded in agriculture is the crop yield, measured as the (quantity or monetary) production per land-use (acres or hectares, for instance).

Research in agricultural productivity has evolved to incorporate a comprehensive set of inputs, including labor, land, capital and purchased intermediate products, to reach multi-factor productivity measures. Total factor productivity (TFP) is measured by "the computation of an index of total output and an index of all factor inputs" (Christensen, 1975). The TFP is affected by technological enhancements, which produces "productivity shocks" (Kydland \& Prescott, 1982), so that output can be increased with no significant change in input intensity. Furthermore, varying levels of total factor productivity can be achieved depending on "how efficiently (...) the inputs are utilized in production" (Comin, 2010).

Efficiency is achieved through maximization of revenues and minimization of costs when there is no other combination of units that could improve production output and input consumption (Farrell, 1957). According to Charnes et al. (1978), when a production unit achieves maximal output for all the indicated inputs "it fulfills the requirements of a production function", reaching "the efficient production possibility frontier". Thus, efficiency is a relative concept, based on comparing the cost-benefit ratio of a production unit with the best practices - that is, with those units that make up the production possibility frontier given an available technology. 
Eco-efficiency incorporates environmental costs to the assessment of efficiency, in order to meet sustainability efforts. Unlike productivity and efficiency, which are concepts well defined by literature and can be assessed by varied quantitative methods, sustainability encompasses less bounded concepts and more complex measurement attributes.

The cornerstone for sustainability definition was offered by the Brundtland Report of the United Nations World Commission on Environment and Development (Brundtland et al., 1987). According to the report, sustainable development is the "development that meets the needs of the present without compromising the ability of future generations to meet their own needs". This definition encompasses both the social needs and the environmental limitations for indefinite human survival.

Thus, sustainability encompasses both physical and human development dimensions. According to Pater and Cristea (2016), the physical dimension of sustainability encompasses space, time, resources, and products. The human development dimension is settled upon economic, environmental, and social pillars - which must be attached to a solid institutional framework (Littig \& Griessler, 2005).

The concept of eco-efficiency tentatively bounds these physical and human development dimensions in order to assess the sustainability of human activities. The World Business Council for Sustainable Development (WBCSD) defined eco-efficiency as the "delivery of competitively priced goods and services that satisfy human needs and bring quality of life, while progressively reducing ecological impacts and resource intensity throughout the life-cycle to a level at least in line with the Earth's estimated carrying capacity" (Schmidheiny, 1992).

Kuosmanen (2005) identifies different approaches for ecoefficiency analysis to address "certain general challenges", which includes the assessment of both economic and environmental impacts, "attributed to commodities (goods and services)" or "to organizations (firms, cities, factories) that produce the commodities". Similarly, Ehrenfeld (2005) notes that eco-efficiency is "applied in practice" at the level of "processes and products (microscale)" or to evaluate "the performance of a company or other organizational entity" or "the performance of a country, region, or other macro-entity".

Among the approaches identified by Kuosmanen (2005) to assess the eco-efficiency of human activities are the Life-Cycle Assessment (LCA), the Cost-Benefit Analysis (CBA) and the Contingent Valuation (CV). But the author argues that these approaches, while adopting quite different methods, "tend to focus on the challenges in isolation"- that is, "focus on a single issue, ignoring other key challenges involved". As such, the author calls for a "more unified approach to eco-efficiency measurement".

Bearing the need of a more comprehensive approach to address the challenges of eco-efficiency, Kuosmanen and Kortelainen (2005) suggested the application of Data Envelopment Analysis (DEA) to quantify economic performance and environmental damage "to construct an encompassing eco-efficiency index".

Data Envelopment Analysis (DEA) is a non-parametric model introduced by Charnes et al. (1978) to evaluate "the performance of a set of peer entities called Decision Making Units (DMUs) which convert multiple inputs into multiple outputs", based on the principles presented by Farrell (1957) to measure efficiency. According to Farrell (1957), efficiency is determined by the set of possible combinations that a unit can produce from the available resources. The efficiency of a DMU is measured by the ratio between its productivity and the productivity of DMUs that display the best possible combination of products and inputs, establishing an efficiency frontier.

A DEA model can be applied either to maximize production while maintaining a stable amount of inputs (denominated output-oriented) or to minimize inputs while maintaining the level of production (input-oriented). The original model was developed to analyze efficiency with constant returns to scale (CRS), assuming that, at the production possibilities frontier, any variation in inputs produces proportional variation in outputs.

The model derives from a fractional programming problem, represented by Equation (1), aimed at estimating the efficiency of DMUo, which must be solved for each of the $k$ DMUs evaluated. The model aims at maximizing the value of the division between the weighted sum of the $s$ outputs and the weighted sum of the $r$ inputs, subject to two restrictions: (i) the efficiency measures of all the units evaluated must be less than or equal to one; and (ii) the most appropriate weights ( $u$ and $v$ ) of the output $(y)$ and input $(x)$ variables need to take non-negative values. 


$$
\operatorname{Max} \phi_{o}=\left[\frac{\sum_{j=1}^{\mathrm{s}} \mathrm{u}_{\mathrm{j}} \mathrm{y}_{\mathrm{jo}}}{\sum_{\mathrm{i}=1}^{\mathrm{r}} \mathrm{v}_{\mathrm{i}} \mathrm{x}_{\mathrm{io}}}\right]
$$

Subject to:

$$
\begin{gathered}
{\left[\frac{\sum_{\mathrm{j}=1}^{\mathrm{s}} \mathrm{u}_{\mathrm{j}} \mathrm{y}_{\mathrm{jk}}}{\sum_{\mathrm{i}=1}^{\mathrm{r}} \mathrm{v}_{\mathrm{i}} \mathrm{x}_{\mathrm{ik}}}\right] \leq 1, \forall \mathrm{k}} \\
\mathrm{u}_{\mathrm{j}} \text { and } \mathrm{v}_{\mathrm{i}} \geq 0, \forall \mathrm{i}, \mathrm{j}
\end{gathered}
$$

To facilitate the calculation, the fractional programming problem is transformed into a linear programming problem. This requires: (i) the transformation of the denominator of the objective function of Equation (1) into a constraint, assigning it a constant value (usually equivalent to 1); and (ii) the linearization of the constraint formulated in a fractional way. The linear programming problem represented in Equation (2) is the input-oriented multiplier model - because it indicates how much to reduce inputs while maintaining the level of production. In the multiplier model, the decision variables are the weights $\left(v_{i}\right.$ and $\left.u_{j}\right)$ assigned to inputs and outputs. They indicate the contribution of each variable in determining the efficiency level.

$$
\operatorname{Max} \phi_{\mathrm{o}}=\sum_{\mathrm{j}=1}^{\mathrm{s}} \mathrm{u}_{\mathrm{j}} \mathrm{y}_{\mathrm{jo}}
$$

Subject to:

$$
\begin{gathered}
\sum_{\mathrm{i}=1}^{\mathrm{r}} \mathrm{v}_{\mathrm{i}} \mathrm{x}_{\mathrm{io}}=1 \\
\sum_{\mathrm{j}=1}^{\mathrm{s}} \mathrm{u}_{\mathrm{j}} \mathrm{y}_{\mathrm{jk}}-\sum_{\mathrm{i}=1}^{\mathrm{r}} \mathrm{v}_{\mathrm{i}} \mathrm{x}_{\mathrm{ik}} \leq 0, \forall \mathrm{k} \\
\mathrm{u}_{\mathrm{j}} \text { and } \mathrm{v}_{\mathrm{i}} \geq 0, \forall \mathrm{i}, \mathrm{j}
\end{gathered}
$$

The original DEA-CRS model was redesigned by Banker et al. (1984) to include variable returns to scale (VRS). In this model, the property of proportionality between inputs and outputs is replaced by a convexity property, which considers increasing or decreasing returns to scale at the efficiency frontier. Equation (3) presents the linear programming problem of the input-oriented multiplier model with variable returns to scale, where, $u^{*}$ is the scale factor: when negative, it indicates increasing returns; when positive, decreasing returns; and, if null, constant returns to scale. The exercises presented in Section 4 of this article use input-oriented DEA-VRS models.

Subject to:

$$
\operatorname{Max} \varphi_{\mathrm{o}}=\sum_{\mathrm{j}=1}^{\mathrm{s}} \mathrm{u}_{\mathrm{j}} \mathrm{y}_{\mathrm{jo}}+\mathrm{u}^{*}
$$

$$
\begin{gathered}
\sum_{\mathrm{i}=1}^{\mathrm{r}} \mathrm{v}_{\mathrm{i}} \mathrm{x}_{\mathrm{io}}=1 \\
\sum_{\mathrm{j}=1}^{\mathrm{s}} \mathrm{u}_{\mathrm{j}} \mathrm{y}_{\mathrm{jk}}+\mathrm{u}^{*}-\sum_{\mathrm{i}=1}^{\mathrm{r}} \mathrm{v}_{\mathrm{i}} \mathrm{x}_{\mathrm{ik}} \leq 0, \forall \mathrm{k} \\
\mathrm{u}_{\mathrm{j}} \text { and } \mathrm{v}_{\mathrm{i}} \geq 0, \mathrm{u}^{*} \in \mathrm{R}
\end{gathered}
$$

Kuosmanen and Kortelainen (2005) argue that DEA models have the advantage "to account for substitution possibilities between different performance criteria and its independence of subjective aggregation weights". In other words, DEA is an objective model in which the weights of economic performance and environmental impacts are allocated in the best possible manner as to achieve the highest eco-efficiency score, regardless of subjective orientation. A decision-making unit is considered eco-efficient when no other weight-combination of economic performance and environmental impacts can result in a better eco-efficiency score.

DEA models have been increasingly applied to eco-efficiency analysis, as is illustrated in the next section of this article, which examines the literature on the quantified eco-efficiency assessment of agricultural systems.

\section{Literature Review on Agricultural Eco-efficiency: Methods and Indicators}

\subsection{Review Procedures}

As argued in the introduction, the literature review conducted in this article follows protocols suggested by Pagani et al. (2015). The review is guided by three main research questions: (i) Which methods/techniques are applied in assessing the eco-efficiency of agricultural systems? (ii) Which statistical variables are used to assess the eco-efficiency of agricultural systems? (iii) For which purpose is eco-efficiency analysis applied in the research of agricultural systems? By tentatively answering these research question, this literature review aims to provide empirical steps for the elaboration of agricultural eco-efficiency indicators, pointing out the benefits and limitations of their application.

The first stage of the review is to establish the criteria for the literature selection, which attends the following sequence. (1) Publication type: articles published in academic journals, available online, in any research area, in English, Portuguese and Spanish. (2) Electronic databases: Web of Science (Clarivate Analytics), Science Direct 
(Elsevier), Scopus (Elsevier), Wiley On-line Library (Wiley) and AGRIS (FAO). (3) time-period: 1992 to 2018. By attending these criteria, the review covers over 15000 academic journals containing articles published since the inception of the eco-efficiency definition.

The literature selection is conducted considering two main thematic axes: Eco-efficiency and Agriculture. The article search is performed in the above-mentioned electronic databases combining a set of keywords evolving from these thematic axes. The search returned 8413 articles under the Eco-efficiency umbrella and 583 articles when keywords from both Eco-efficiency and Agriculture axes were combined.

The search results were then filtered to eliminate duplicates and the 323 remaining articles had their titles and abstracts analyzed in order to eliminate articles not adherent to the focus of the literature review-that is, the quantitative assessment of agricultural eco-efficiency. The selection, search and filtering steps resulted in 90 articles (Figure 1) that were submitted to full-text examination in order to address the three suggested research questions mentioned above.

\begin{tabular}{|c|c|c|c|c|}
\hline Editor & Database & $\begin{array}{l}\text { \# articles under } \\
\text { Eco-efficiency }\end{array}$ & & $\begin{array}{c}\# \text { articles under } \\
\text { Eco-efficiency + } \\
\text { Argriculture }\end{array}$ \\
\hline Clarivate & Web of Science & 1934 & $\rightarrow$ & 89 \\
\hline Elsevier & Science Direct & 2558 & $\rightarrow$ & 161 \\
\hline Elsevier & Scopus & 2233 & $\rightarrow$ & 165 \\
\hline Wiley & Wiley & 1596 & $\rightarrow$ & 77 \\
\hline \multirow[t]{2}{*}{ FAO } & AGRIS & 92 & $\rightarrow$ & 91 \\
\hline & & 8413 & $\rightarrow$ & $\begin{array}{c}583 \\
\downarrow \\
\text { Eliminate duplicates } \\
\downarrow \\
323 \\
\downarrow \\
\text { Eliminate articles not } \\
\text { adherent to the focus of the } \\
\text { literature review } \\
\downarrow \\
90\end{array}$ \\
\hline
\end{tabular}

Figure 1. Article search results and filtering

\subsection{Main Findings and Discussion}

The 90 articles fully examined varied on geographical scope, with Europe (52 articles) and Asia (16 articles) being the host of the first author's institutions in more than $75 \%$ of the articles. The remaining articles were spread between North America (8), Oceania (7), South America (5) and the Middle East (2). Spain (13 articles), Switzerland (11), Italy (8) and China (8) stand out as the most prolific countries.

Although most of the articles come from European institutions, the most cited and the highest impact factor articles are, on average, from North America and Oceania, followed by Europe, Asia, and South America. The first author's nationality and the location of the objects analyzed have similar geographical scope.

Research areas are concentrated in agricultural economics and management, as well as in environmental sciences. The articles were published in more than 40 journals, with 13 journals publishing at least two articles. The Journal of Cleaner Production outstands with 18 articles published, followed by The Journal of Environmental Management (7 articles), Sustainability (7), Agricultural Systems (6), and Ecological Economics (4).

No articles published before 2003 met the selection criteria. The number of publications regarding quantitative assessment of agricultural systems has been increasing significantly since 2010 (Figure 2). 


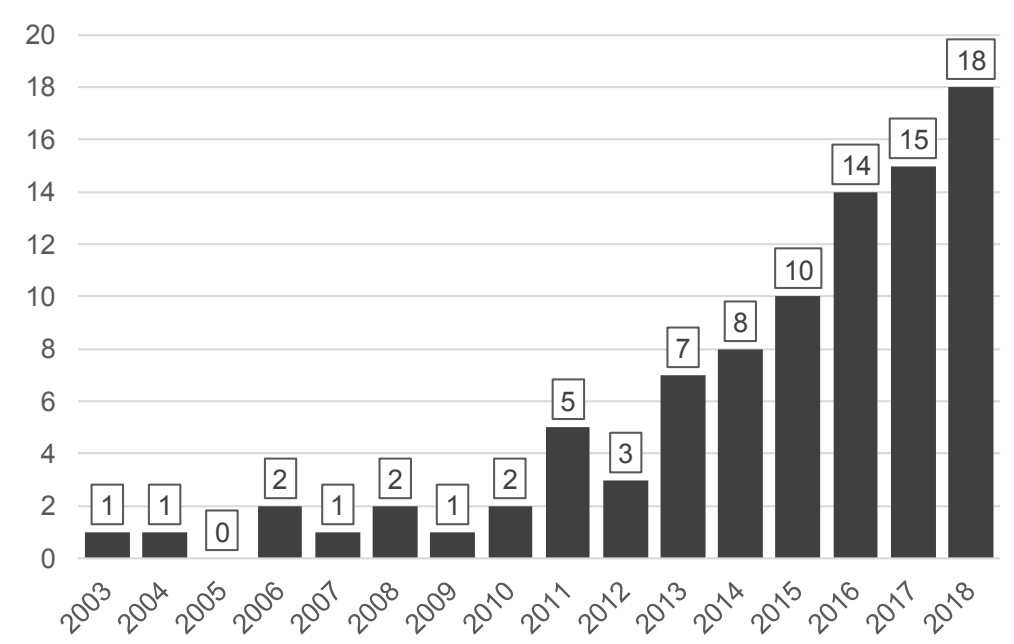

Figure 2. Number of publications per year

The analytical examination of the selected articles reveals two preferred methods of eco-efficiency assessment. Life Cycle Assessment (LCA) and Data Envelopment Analysis (DEA) - either applied individually or combined with each other or with other methods - are present in 67 of the 90 articles (Figure 3).

Carbon Footprint (CF) and Stochastic Frontier Analysis (SFA) are applied more than twice, whereas other methods-including Balance Scorecard (BSC), Cost-Benefit Analysis (CBA), Contingent Valuation (CV) and unreplicated econometric models - are not found in more than two articles.

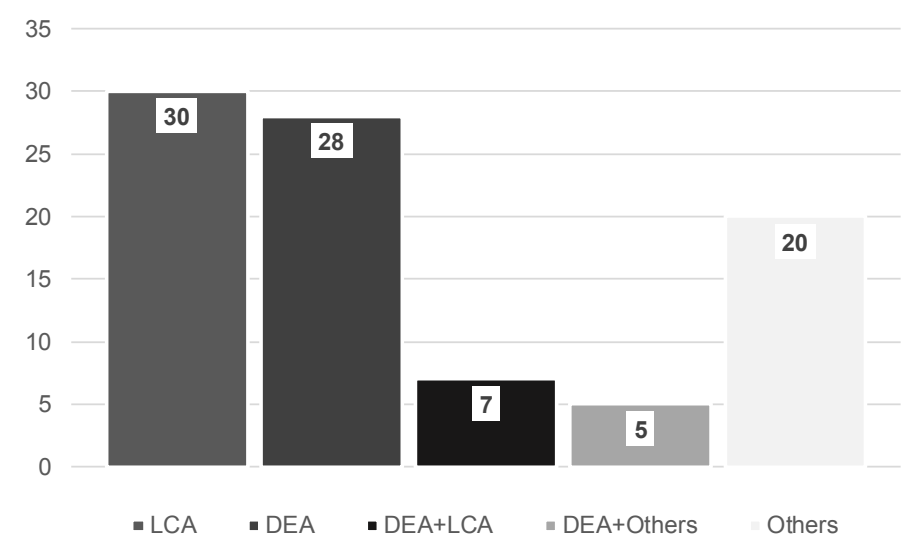

Figure 3. Number of publications according to method applyed

The impact factor of the examined articles was calculated following protocols recommended by Pagani et al. (2015). The results show no significant difference between the impact factor of the articles which apply the main assessment methods found in literature (i.e., DEA and LCA). The impact factor of the articles that resorted to other methods was found to be lower (Figure 4). 


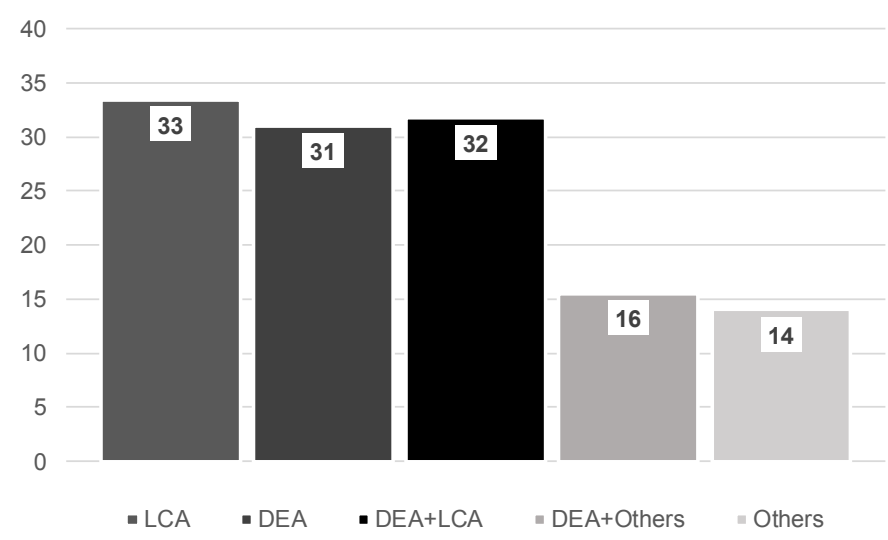

Figure 4. Impact factor of the article by method of analysis

Life Cycle Assessment (LCA) was dominant up to 2009. The main reason for this early-stage dominance is that LCA had close ties with the eco-efficiency concept in so far as it was a widely used assessment method for "standardization in the field of environmental management systems" as well as a "tool in support of sustainable development" (International Standardization Organization [ISO], 2012).

Indeed, in 1993 the International Organization for Standardization created the Technical Committee 207, which established, under the sub-committee number 5, the guidelines for the Life Cycle Assessment. The LCA guidelines later evolved into the ISO 14045 certification, which "describes the principles, requirements and guidelines for eco-efficiency assessment of product systems" (ISO, 2012).

The LCA can be described as a quantitative analysis covering a holistic set of inputs used and products and externalities generated throughout the entire life cycle of a product or a production process - often called from "cradle to grave". This method is significantly biased towards the assessment of environmental impacts, neglecting the assessment of the economic efficiency (Kuosmanen, 2005). Since 2010, the more comprehensive Data Envelopment Analysis (DEA) has emerged as the prominent method applied to eco-efficiency assessment-although the Life Cycle Assessment (LCA), far from being abandoned, has also been attracting increasing research attention (Figure 5).

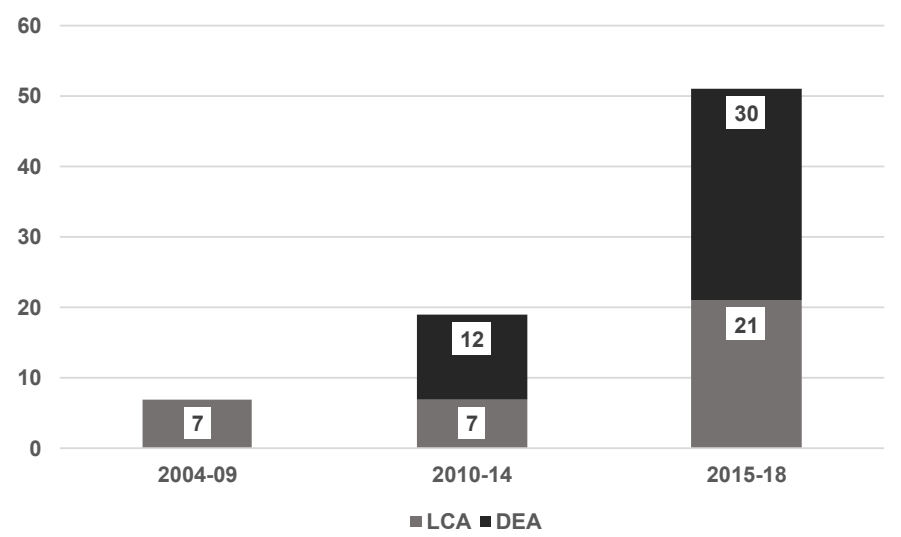

Figure 5. Number of articles by selected methods and periods

The main reason behind the sharing importance of these two methods in the eco-efficiency analysis is that they are preferred for specific intentions and for different categories of objects. Life Cycle Assessment has a more microanalytic approach, generally applied to assess the environmental impacts of products and processes. Data Envelopment Analysis, more focused on the efficient combination of both economic value and environmental impacts, with no subjective weight attribution, has a more macro perspective and is mostly applied to decision-making units (DMU), such as farms (when analyzing agricultural eco-efficiency), municipalities, regions, countries (Figure 6). 


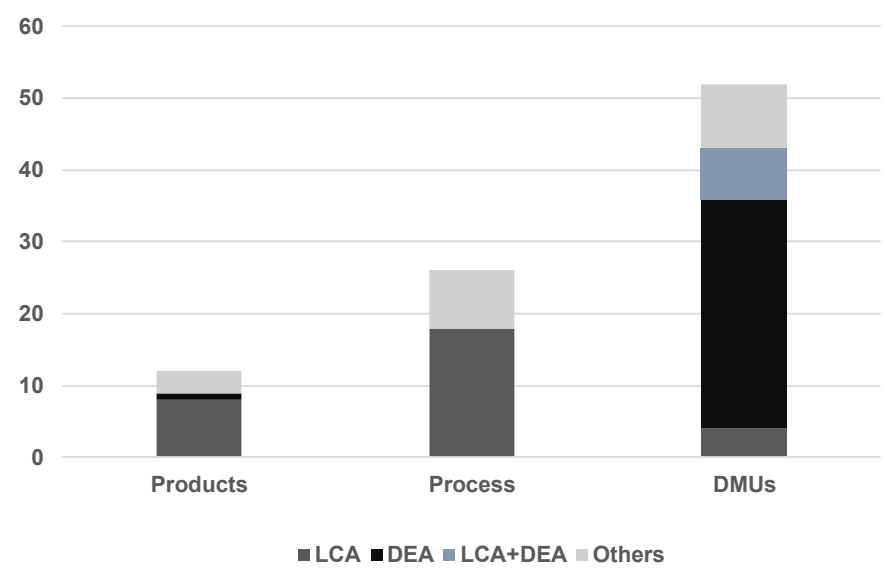

Figure 6. Number of articles by object of study and method applied

The differences found in these two methods also lead them to diverge in dataset choices. Primary data prevail in the LCA method, whereas secondary data are dominant in DEA. Nevertheless, these two techniques share a wide range of economic and environmental variables - although both fail to incorporate the social dimension of sustainability into the eco-efficiency analysis.

The examination of the selected articles on agricultural eco-efficiency reveals a wide set of statistical variables that can be grouped in three main categories: economic output, production inputs and environmental outputs.

(1) Economic output indicators can be expressed in non-monetary or monetary terms.

Non-monetary variables are usually regarded when comparing the eco-efficiency of similar products or peer units which produce the same goods. Indicators, such as harvested weight, are not suitable for comparisons between crops of different cultures - once agricultural products have different physical characteristics. An acreage of harvested sugarcane, for example, will surely be much heavier than an acreage of harvested cotton, but not necessarily more productive.

Monetary indicators are more suitable to compare products with different physical characteristics or units with diversified production. Sale revenues, agricultural gross value added, and primary sector Gross Domestic Product are the main indicators found in the literature review. Nevertheless, price fluctuation inherent to agricultural products - due to external shocks (notably of climatic nature) and seasonality - can lead to distortions in the assessment of economic performance through these monetary indicators. When material indicators are suitable, monetary indicators are generally disregarded.

(2) Production inputs can be divided into two subcategories: direct and indirect inputs.

Direct inputs, as the terminology suggests, are inputs directly used in the agricultural activity. These inputs can be divided into four types: land-use, labor inputs, capital (or equipment) utilization, and purchased intermediate inputs (such as seeds, fertilizers, pesticides).

Land-use is generally measured by the area used for production, which is a non-monetary variable. Monetary value of land was disregarded by all but three of the articles examined, due to regional property price differences. The few monetary examples of land input are either rental or depreciation costs.

Labor inputs found in the literature review include the number of workers and hours/days worked, when non-monetary variables are considered, or the cost of labor (such as wages and compensations) when monetary variables are regarded.

Similarly, capital equipment can be calculated either by material variables (the number of machines or the combined power of the machines) or monetary variables (the capital depreciation of the equipment). The same applies to intermediate inputs - for instance, the amount (in weight) or the cost (in monetary terms) of fertilizers and pesticides.

The literature review found that it is preferred, but not mandatory, to compare economic output and direct production inputs in the same terms (either material or monetary). 
The indirect production inputs most regarded by the articles reviewed refer to energy consumption or costs, generally fuel and electricity. Other indirect indicators eventually considered include natural resources (notably irrigated water) and governmental subsidies.

(3) Environmental outputs are divided into positive and negative outputs.

Examples of positive outputs, by far less regarded in the articles reviewed, are preserved areas, reforestation, and recovery of springs and degraded areas. All the examples were found to be expressed in non-monetary terms.

Negative environmental outputs are far more abundant in the literature of eco-efficiency assessment of agricultural systems. The most regarded indicators are: (i) greenhouse gas (GHG) or carbon dioxide $\left(\mathrm{CO}_{2}\right)$ emissions, usually following methodological guidelines offered by The Intergovernmental Panel on Climate Change (IPCC, 2006); and (ii) nitrogen (N) or nitrogen-phosphorus-potassium (NPK) balance, measured by the Soil Surface Balance Method (OECD, 2001).

Many other negative environmental indicators found in the reviewed articles include: (i) the intensity of pesticide use, either measured by the weight of active ingredients or through the method of Environmental Impact Quotient of Pesticides (EIQP) developed by Kovach et al. (1992); (ii) impact on biodiversity, usually calculated by the Shannon Diversity Index (Spellerberg \& Fedor, 2003); and (iii) degraded areas, soil erosion, water depletion, and waste and residues.

The eco-efficiency analysis of any product, process or decision-making unit should contain at least one variable from all three main categories. Ideally, a more comprehensive analysis should include as many indicators as possible.

Indicator choices for the eco-efficiency assessment of agriculture are often performed based on two relevant factors. First, data quality and availability — which can be regarded as the main limitation for quantitative eco-efficiency assessment. Second, the purposes for which the eco-efficiency analysis is applied to agricultural systems.

The paramount motivation for applying eco-efficiency analysis is the sustainability assessment of economic activities. Surrounding this central motivation, many specific objectives of the analysis are found through this literature review (Figure 7). One prominent objective, found both when LCA or DEA were applied (but somewhat more frequent with the latter), is guidance for environmental public policies - notably in European studies.

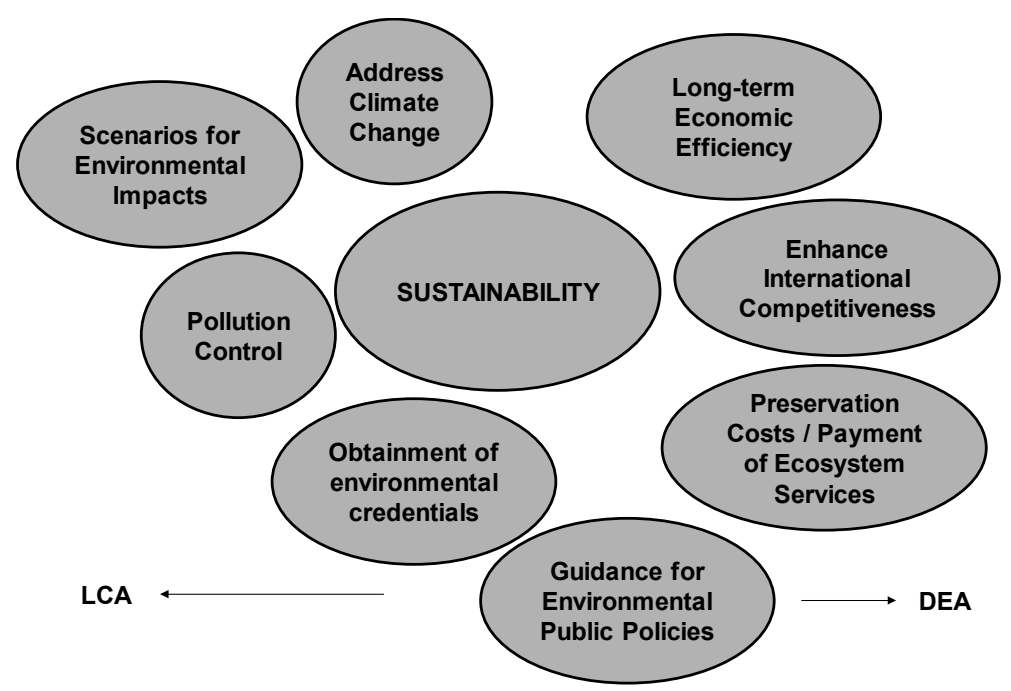

Figure 7. Objetives of the eco-efficiency analysis of agricultural systems

Picazo-Tadeo et al. (2011), for instance, summarize the purpose of their studies as such:

"Assessing eco-efficiency might help policy-makers to design agricultural policies more capable of achieving the general objective of agricultural sustainability and, particularly, the sustainability of specific agricultural systems" (p. 1163). 
Tendall and Gaillard (2015) call for greater integration between environmental and social policies, even though they have failed to include social indicators in their eco-efficiency modeling:

"There is (...) a need for adequate policy intervention if productivity and ecoefficiency are to be maintained under the future climate, and climate change mitigation is to be achieved. Our results (...) show that the environmental impacts of agricultural adaptation to climate change are influenced by socio-economic scenarios as much as by climate change scenarios: policies affecting socio-economic aspects may have a high potential to counter the effects of adaptation to climate change" (p. 49).

Vlontzosa and Pardalos (2017) suggest that quantified eco-efficiency could be a useful tool for ex-ante examination of public policies intended to reduce environmental damages:

"The quantification of environmental performance could be a starting point for planning and implementing policies and incentives towards a more efficient usage of energy related inputs in agricultural production and assess the impact of these policies before their implementation" (p. 160).

Kuosmanen (2014) acknowledges the need to further deepen research to reach a "more comprehensive eco-efficiency or productivity analysis and for the evaluation and design of agri-environmental policies in Europe" (pp. 68). Other authors (Aldonondo-Ochoa et al., 2014) and many Chinese studies also offer recommendations for public policies (Zhou et al., 2013; Wang et al., 2014; Xing et al., 2018).

Alongside public policy guidance, recommendations for enhancing economic and environmental efficiency of decision-making units stands out as another specific purpose commonly found in the reviewed articles with higher impact factor. Most articles focus on crop or dairy farms (Nemecek et al., 2011; Jan et al., 2012; Shortall \& Barnes, 2013; Hochman et al., 2014; Kulak et al., 2015; Masuda, 2016; Pereira et al., 2016). But geographical regions and countries are also broadly studied (Halkos et al. 2006; Repar et al., 2017; Pang et al., 2016; Pokhrel \& Soni, 2017).

Pollution control was also found as an outstanding research purpose (Kuosmanen \& Kuosmanen, 2013; Kuo et al., 2014; He, Wan et al., 2016; Reboledo-Leiva et al., 2017). Also related to greenhouse gas emission and climate change, some articles aimed at building scenarios under a future climate (Niero et al., 2015; Vlontzos \& Pardalos, 2017). Other research included assessment of preservation costs and payment of ecosystem services (Rosano-Peña et al., 2018) and obtainment of environmental credentials (Müller et al., 2013).

It is important to notice that many authors, from a wide geographical range, have acknowledged that the eco-efficiency analysis of agricultural systems face important limitations due to limited availability of reliable and harmonized input data (Rodrigues et al., 2010; Bengtsson \& Seddon, 2012; Todorovic et al., 2016; Corrado et al., 2018; Xing et al., 2018). Vlontzos and Pardalos (2017), commenting on their research, alert that "there is a need for further research on both the architecture of the model, and on the inputs being used, in order to improve its reliability and applicability".

\section{A Simple Framework for the Eco-efficiency Analysis of the Brazilian Agriculture}

In order to achieve the objective of highlighting the benefits and limitations of eco-efficiency applied to agriculture, this fourth section of the article delivers three simple models in order to encompass the proposed eco-efficiency framework for Brazilian agriculture. Brazil has a continental size. The exercises conducted in this article compare the performance of the Brazilian economy at a state-level. Brazil is divided in 27 states, officially denominated as Units of the Federation (UFs).

The first exercise is aimed at delivering a single-factor productivity measure for each UF, tentatively avoiding distortions associated with different physical characteristics or price fluctuations of agricultural products. The second exercise includes a broader set of outputs and inputs into an input-oriented DEA considering variable returns to scale in order to obtain a technical efficiency score for the UFs. In the third model, environmental variables are included in the input-oriented DEA with variable returns to scale, thus encompassing both technical and environmental dimensions, in order to deliver eco-efficiency scores of all 27 Brazilian UFs. DEA is chosen once the literature review revealed this method as the most adequate for the eco-efficiency analysis of geographical regions.

\subsection{Single-Factor Productivity: Index of Weighted Agricultural Productivity (IWAP)}

The first model, aimed at delivering a land productivity measure for the Brazilian economy, compares the weight of production (in tons) with harvested area (hectares). The source of these data is the 2017 annual agricultural production survey of the Brazilian national statistics institute (IBGE). 
To avoid distortions related to physical production differences and price fluctuations, an index of relative agricultural land productivity is constructed by comparing the productivity of each agricultural product harvested in the UFs with the national average productivity of the same products. This product-by-product productivity ratio for each UF is then weighted by the proportion of the harvested area dedicated to each product in order to provide an index of weighted agricultural productivity (IWAP) for each UF, as illustrated by Equation 4-where: $y_{n}$ is production in tons per hectare of cultivated area with each product $n$ in the respective UF; $Y_{n}$ is production in tons per hectare of cultivated area with each product $n$ in Brazil; and $a_{n}$ is the proportion of the cultivated area with each product $\boldsymbol{n}$ relative to the total area cultivated in the respective UF.

$$
\operatorname{IWAP}=\sum_{\mathrm{n}=1}^{\mathrm{n}}\left(\frac{\mathrm{y}_{\mathrm{n}}}{\mathrm{Y}_{\mathrm{n}}} * \mathrm{a}_{\mathrm{n}}\right)
$$

Figure 8 shows a map with the weighted index of agricultural land productivity in Brazil by UF. High agricultural land productivity states are concentrated in the more developed Southern and South-Eastern Regions, whereas lower productivity index states are concentrated in the poorer North-Eastern Region. Large scale monocultures, such as soybeans, corn, and sugarcane prevail in regions with higher productivity. Smaller farms, which apply less technology, prevail in regions where productivity scores are lower.

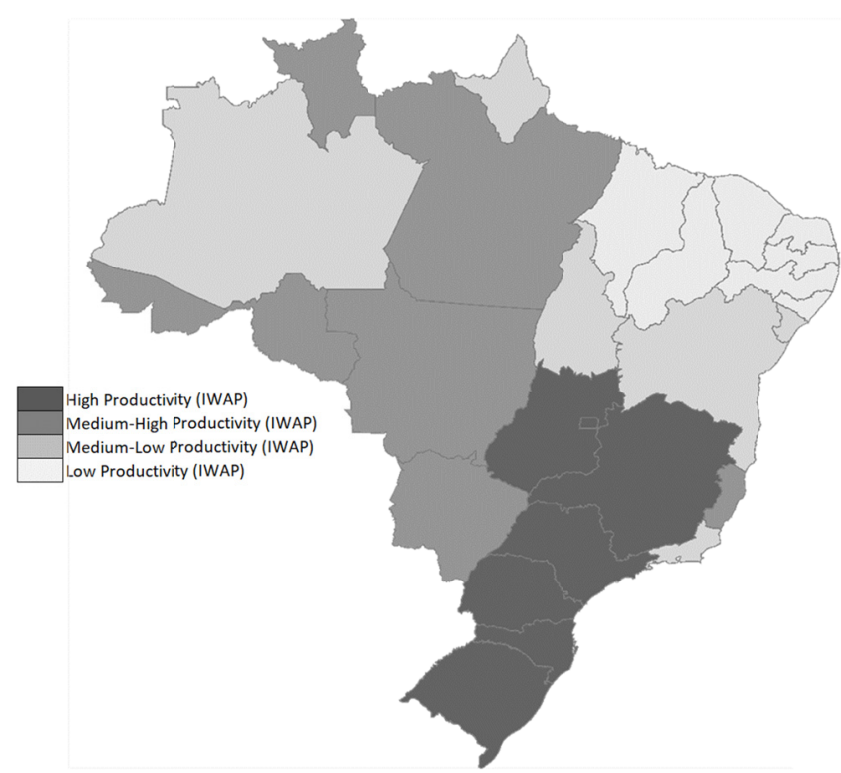

Figure 8. Brazil, agricultural index of weighted agricultural productivity (IWAP) bu UF

\subsection{Technical Efficiency Assessment}

The technical efficiency assessment model presented in this article uses data from the IBGE 2017 agricultural census. Output data refer to revenues from agricultural activities (in Brazilian Real-BRL), whereas the inputs considered are land-use (in hectares), labor expenses (wages and compensation, in BRL), capital inputs (in number of agricultural machinery), direct intermediate expenses (seeds, fertilizers, pesticides etc., in BRL) and indirect expenses (energy, storage, transport etc., in BRL).

The results of the input-oriented DEA-VRS are illustrated in Figure 9. Some UFs in the Northern Region have relatively low level of land productivity but have higher technical efficiency, suggesting they have better input allocation than other more developed UFs in the Southern and South-Eastern Regions which do not perform so well in terms of technical efficiency. Excessive use of intermediate inputs in monocultures, such as pesticides, explains at a good degree the lower technical efficiency scores in some of these more developed regions. 


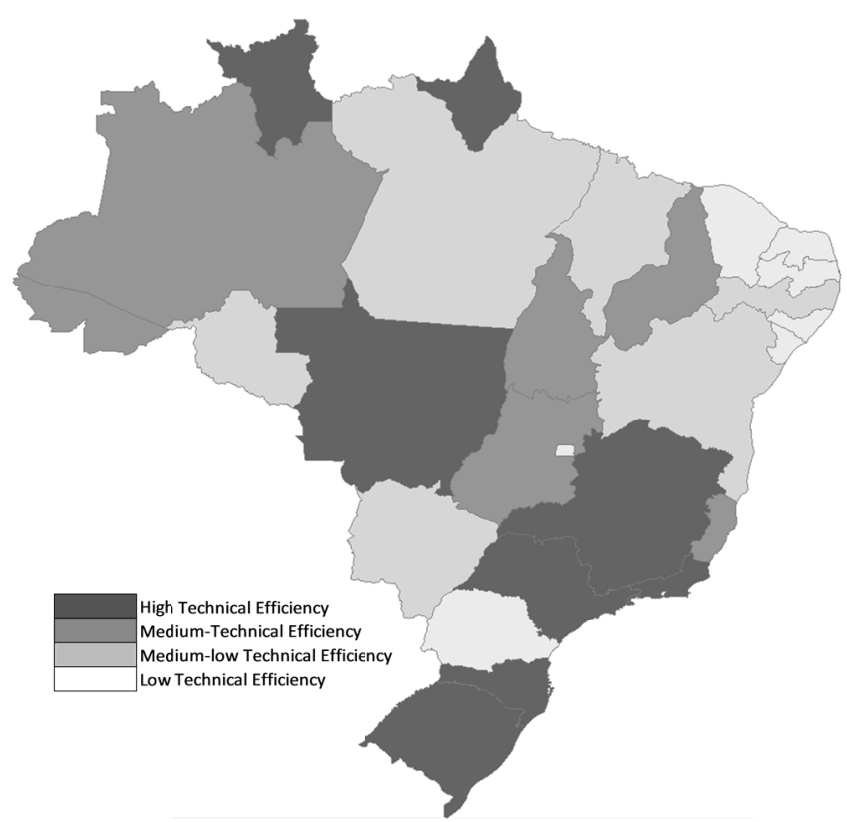

Figure 9. Brazil, technical efficiency of agriculture by UF

\subsection{Agricultural Eco-efficiency of the Brazilian UFs}

To achieve the objective of incorporating the environmental dimension into the efficiency analysis, one desirable and two undesirable indicators are used to obtain environmental scores for all 27 UFs. The desirable output considered, representing compliance with environmental law, is the ratio between the effective area of preserved land and the legally required preserved land (Imaflora, 2017). The undesirable indicators, treated as inputs in the model, are: greenhouse gas emissions from agriculture, measured in $\mathrm{CO}_{2}$ equivalent (SEEG, 2017); and the intensity of pesticide use, measured by the relation between the weight of active ingredients and harvested area (IBAMA, 2017).

The environmental scores obtained through input-oriented DEA-VRS, illustrated in Figure 10, show that many of the most productive and technically efficient UFs have low performance in the environmental dimension. On the other hand, many technically inefficient UFs from the North-Eastern Region perform better where environmental aspects are regarded.

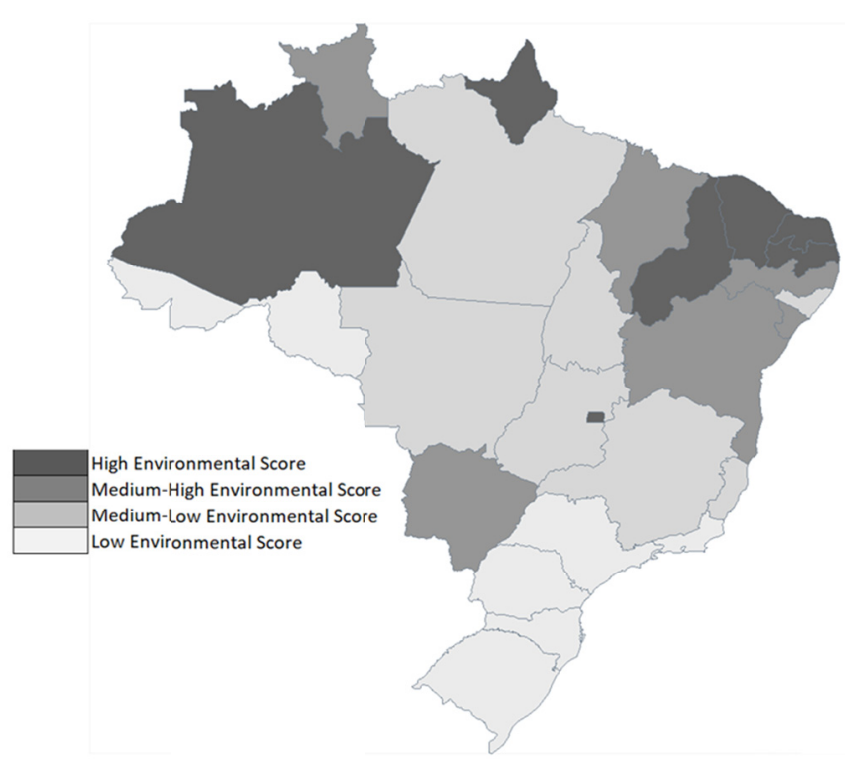

Figure 10. Brazil, agricultural environmental scores by UF 
The input-oriented DEA-VRS model was then run considering both the technical aspects and the environmental dimension, delivering agricultural eco-efficiency scores for all 27 Brazilian UFs. As shown in Figure 11, the environmental impacts have significantly lowered the overall eco-efficiency scores of some highly productive and technically efficient agricultural units in the more development regions of Brazil.

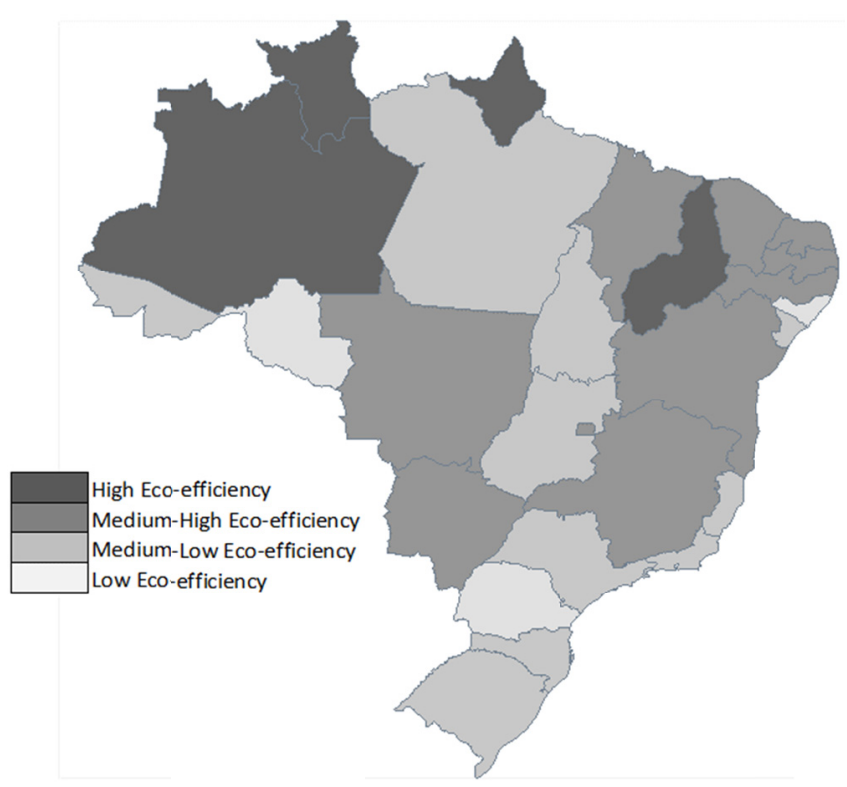

Figure 11. Brazil, agricultural eco-efficiency by UF

This illustrates the importance of the eco-efficiency analysis to address inadequate and degrading environmental practices of some highly productive units. More technically and environmentally balanced practices would increase the chances of achieving a more sustainable agricultural system.

Ideally, the eco-efficiency analysis should be applied to a larger set of units and encompass a more comprehensive set of indicators, including the disregarded social dimension. Lower availability of reliable data for smaller-scale units (such as municipalities and farms) is a foremost limitation for eco-efficiency analysis.

\section{Final Considerations}

Eco-efficiency assessment is an analytical tool, under ongoing development and increasing research attention, to support public and private decision making in order to direct economic activities towards sustainability.

The literature review conducted in this article revealed a wide range of applications for eco-efficiency analysis, although geographical focus is concentrated in Europe and, more recently, in emerging Asia. Eco-efficiency assessment of agricultural tools is indicated for public policy guidelines, for environmental pollution control, to enhance the efficiency of decision-making units, to calculate recompensation for preservation efforts, to build scenarios in order to address climate change, among other initiatives to foster sustainability.

The concept of sustainability encompasses three pillars - economic, environmental, and social pillars-but eco-efficiency analysis is deficient in social assessment of economic activities, especially when agricultural systems are regarded. This is one the main limitations of eco-efficiency analysis.

Another important limitation, widely acknowledged in literature, is the limited availability of reliable and harmonized data - as illustrated by the simple framework presented in the previous section. This limitation is particularly significant when the object of the analysis are agricultural systems.

Finally, there seems to be no deterministic relation between eco-efficiency and sustainability-that is, an eco-efficient unit is not necessarily sustainable when the four physical dimensions (space, time, resources, products) and all three pillars of human development (economic, environmental, social) are regarded. This, because efficiency is a relative measure, which compares the performance of similar products, processes or peer decision making units against best practices (which can be the most eco-efficient, but not necessarily sustainable). 
Nevertheless, eco-efficient units have higher probability of becoming sustainable - a stochastic relation which implies that eco-efficiency can be successfully applied to identify economic inefficiencies and unwanted environmental costs (for both degradation and preservation).

This article concludes by suggesting further research to improve the quality of economic, social, and environmental indicators and to enhance the methods, models, and techniques applied to the eco-efficiency analysis of agricultural systems.

Another topic for future research could include the examination of the factors exogenous to the production function which can influence the eco-efficiency of decision-making units. This could be very important, particularly, to assess the eco-efficiency of countries, or regions within a country, with different socio-economic and edaphoclimatic characteristics.

\section{References}

Aldonondo-Ochoa, A. M., Casanovas-Oliva, V. L., \& Arandia-Miura, A. (2014). Environmental efficiency and the impact of regulation in dryland organic vine production. Land Use Policy, 36, 275-284. https://doi.org/ 10.1016/j.landusepol.2013.08.010

Banker, R. D., Charnes, A., \& Cooper, W. W. (1984). Some models for the estimation of technical and scale inefficiencies in Data Envelopment Analysis. Management Science, 30, 1078-1092. https://doi.org/10.1287/ mnsc.30.9.1078

Bengtsson, J., \& Seddon, J. (2013). Cradle to retailer or quick service restaurant gate life cycle assessment of chicken products in Australia. Journal of Cleaner Production, 41, 291-300. https://doi.org/10.1016/ j.jclepro.2012.09.034

Brundtland, G. H., Khalid, M., Agnelli, S., Al-Athel, S. A., Chidzero, B., \& Fadika, L. M. (1987). Our common future. World Commission on Environment and Development. Oxford: Oxford University Press.

Charnes, A., Cooper, W. W., \& Rhodes, E. (1978). Measuring the efficiency of decision-making units. European Journal of Operational Research, 2(6), 429-444. https://doi.org/10.1016/0377-2217(78)90138-8

Christensen, L. (1975). Concepts and measurement of agricultural productivity. American Journal of Agricultural Economics, 57(5), 910-915. https://doi.org/10.2307/1239102

Comin, D. (2010). Total factor productivity. In S. N. Durlauf \& L. E. Blume (Eds.), Economic Growth. The New Palgrave Economics Collection, Palgrave Macmillan, London. https://doi.org/10.1057/9780230280823_32

Corrado, S., Castellani, V., Zampori, L., \& Sala, S. (2018). Systematic analysis of secondary life cycle inventories when modelling agricultural production: A case study for arable crops. Journal of Cleaner Production, 172, 3990-4000. https://doi.org/10.1016/j.jclepro.2017.03.179

Costa, M. P., Schoeneboom, J. C., Oliveira, S. A., Viñas, R. S., \& De Medeiros, G. A. (2018). A socio-eco-efficiency analysis of integrated and non-integrated crop-livestock-forestry systems in the Brazilian Cerrado based on LCA. Journal of Cleaner Production, 171, 1460-1471. https://doi.org/10.1016/ j.jclepro.2017.10.063

Ehrenfeld, J. R. (2005). Eco-efficiency: Philosophy, Theory, and Tools. Journal of Industrial Ecology. Volume 9 Issue 4, pp. 6-8. https://doi.org/10.1162/108819805775248070

Farrell, M. J. (1957). The measurement of productive efficiency. Journal of the Royal Statistic Society, Series A (General), 120, 253-290. https://doi.org/10.2307/2343100

Halkos, G. E., Tzeremes, N. G., \& Kourtzidis, S. A. (2016). Measuring Sustainability Efficiency Using a Two-Stage Data Envelopment Analysis Approach. Journal of Industrial Ecology, 20(5), 1159-1175. https://doi.org/10.1111/jiec. 12335

He, J., Wan, Y., Feng, L., Ai, J., \& Wang, Y. (2016). An integrated data envelopment analysis and emergy-based ecological footprint methodology in evaluating sustainable development, a case study of Jiangsu Province, China. Ecological Indicators, 70, 23-34. https://doi.org/10.1016/j.ecolind.2016.05.042.

Hochman, Z., Prestwidge, D., \& Carberry, P. S. (2014). Crop sequences in Australia's northern grain zone are less agronomically efficient than implied by the sum of their parts. Agricultural Systems, 129, 124-132. https://doi.org/10.1016/j.agsy.2014.06.001 
IBAMA (Instituto Brasileiro do Meio Ambiente e dos Recursos Naturais Renováveis). (2017). Relatório de comercialização de agrotóxicos. Retrieved from https://www.ibama.gov.br/agrotoxicos/relatorios-de-come rcializacao-de-agrotoxicos

ILO (International Labor Organization). (2017). Labor Force Estimates and Projections: Key Trends. Retrieved from https://www.ilo.org/ilostat-files/Documents/LFEPbrief.pdf

Imaflora (Instituto de Manejo e Certificação Florestal e Agrícola). (2017). Atlas da Agropecuária Brasileira. Retrieved from http://www.imaflora.org/index.php

IPCC (Intergovernamental Panel on Climate Change). (2006). In H. S. Eggleston, L. Buendia, K. Miwa, T. Ngara, \& K. Tanabe (Eds.), 2006 IPCC Guidelines for National Greenhouse Gas Inventories. Prepared by the National Greenhouse Gas Inventories Programme, IGES, Japan. Retrieved from https://www.ipcc-nggip. iges.or.jp/public/2006gl

IPCC (Intergovernamental Panel on Climate Change). (2014). In R. K. Pachauri \& L. A. Meyer (Eds.), Climate Change 2014: Synthesis Report (p. 151). Contribution of Working Groups I, II and III to the Fifth Assessment Report of the Intergovernmental Panel on Climate Change. IPCC, Geneva, Switzerland.

ISO (International Organization for Standardization). (2012). ISO/TC 207/SC 1, Environmental Management Systems.

Jan, P., Dux, D., Lips, M., Alig, M., \& Dumondel, M. (2012). On the link between economic and environmental performance of Swiss dairy farms of the alpine area. International Journal of Life Cycle Assessment, 17(6), 706-719. https://doi.org/10.1007/s11367-012-0405-z

Kovach, J., Petzoldt, C, Degni, J., \& Tette, J. (1992). A method to measure the environmental impact of pesticides. New York Food and Life Science Bulletin (Number 139). New York, USA.

Kulak, M., Nemecek, T., Frossard, E., Chable, V., \& Gaillard, G. (2015). Life cycle assessment of bread from several alternative food networks in Europe. Journal of Cleaner Production, 90, 104-113. https://doi.org/ 10.1016/j.jclepro.2014.10.060

Kuo, H.-F., Chen, H.-L., \& Tsou, K.-W. (2014). Analysis of Farming Environmental Efficiency Using a DEA Model with Undesirable Outputs. APCBEE Procedia, 10, 154-158. https://doi.org/10.1016/j.apcbee. 2014.10.034

Kuosmanen, N. (2014). Estimating stocks and flows of nitrogen: Application of dynamic nutrient balance to European agriculture. Ecological Economics, 108, 68-78. https://doi.org/10.1016/j.ecolecon.2014.10.008

Kuosmanen, N., \& Kuosmanen, T. (2013). Modeling cumulative effects of nutrient surpluses in agriculture: A dynamic approach to material balance accounting. Ecological Economics, 90, 159-167. https://doi.org/ 10.1016/j.ecolecon.2013.03.016

Kuosmanen, T. (2005). Measurement and Analysis of Eco-efficiency: An Economist's Perspective. Journal of Industrial Ecology, 9(4), 15-18. https://doi.org/10.1162/108819805775248025

Kuosmanen, T., \& Kortelainen, M. (2005). Measuring Eco-efficiency of Production with Data. Journal of Industrial Ecology, 9(4), 59-72. https://doi.org/10.1162/108819805775247846

Kydland, E., \& Prescott, E. C. (1982). Time to Build and Aggregate Fluctuations. Econometrica, 50(6), 1345-1370. https://doi.org/10.2307/1913386

Littig, B., \& Griessler, E. (2005). Social sustainability: a catchword between political pragmatism and social theory. International Journal of Sustainable Development, 8(1/2), 65. https://doi.org/10.1504/IJSD. 2005.007375

Masuda, K. (2016). Measuring eco-efficiency of wheat production in Japan: A combined application of life cycle assessment and data envelopment analysis. Journal of Cleaner Production, 126, 373-381. https://doi.org/ 10.1016/j.jclepro.2016.03.090

Müller, K., Holmes, A., Deurer, M., \& Clothier, B. E. (2015). Eco-efficiency as a sustainability measure for kiwifruit production in New Zealand. Journal of Cleaner Production, 106, 333-342. https://doi.org/ 10.1016/j.jclepro.2014.07.049

Nemecek, T., Dubois, D., Huguenin-Elie, O., \& Gaillard, G. (2011). Life cycle assessment of Swiss farming systems: I. Integrated and organic farming. Agricultural Systems, 104(3), 217-232. https://doi.org/10.1016/ j.agsy.2010.10.002 
Niero, M., Ingvordsen, C. H., Peltonen-Sainio, P., Jalli, M., Lyngkjaer, M. F., Hauschild, M. Z., \& Jorgensen, R. B. (2015). Eco-efficient production of spring barley in a changed climate: A Life Cycle Assessment including primary data from future climate scenarios. Agricultural Systems, 136, 46-60. https://doi.org/10.1016/j.agsy.2015.02.007

OECD (The Organisation for Economic Co-operation and Development). (2001). National Soil Surface Nitrogen Balances (p. 20).

Pagani, R. N., Kovaleski, J. L., \& Resende, L. M. (2015). Methodi Ordinatio: A proposed methodology to select and rank relevant scientific papers encompassing the impact factor, number of citations, and year of publication. Scientometrics, 105, 2109. https://doi.org/10.1007/s11192-015-1744-x.

Pang, J., Chen, X., Zhang, Z., \& Li, H. (2016). Measuring eco-efficiency of agriculture in China. Sustainability (Switzerland), 8(4). https://doi.org/10.3390/su8040398

Pater, L. R., \& Cristea, S. L. (2016). Systemic Definitions of Sustainability, Durability and Longevity. Procedia-Social and Behavioral Sciences, 221, 362-371. https://doi.org/10.1016/j.sbspro.2016.05.126

Pereira, A., Carballo-Penela, A., González-López, M., \& Vence, X. (2016). A case study of servicizing in the farming-livestock sector: Organisational change and potential environmental improvement. Journal of Cleaner Production, 124, 84-93. https://doi.org/10.1016/j.jclepro.2016.02.127

Picazo-Tadeo, A. J., Gómez-Limón, J. A., \& Reig-Martínez, E. (2011). Assessing farming eco-efficiency: A Data Envelopment Analysis approach. Journal of Environmental Management, 92(4), 1154-1164. https://doi.org/ 10.1016/j.jenvman.2010.11.025

Pokhrel, A., \& Soni, P. (2017). Performance analysis of different rice-based cropping systems in tropical region of Nepal. Journal of Environmental Management, 197, 70-79. https://doi.org/10.1016/j.jenvman.2017. 03.035

Rebolledo-Leiva, R., Angulo-Meza, L., Iriarte, A., \& González-Araya, M. C. (2017). Joint carbon footprint assessment and data envelopment analysis for the reduction of greenhouse gas emissions in agriculture production. Science of the Total Environment, 593-594, 36-46. https://doi.org/10.1016/j.scitotenv.2017. 03.147

Repar, N., Jan, P., Dux, D., Nemecek, T., \& Doluschitz, R. (2017). Implementing farm-level environmental sustainability in environmental performance indicators: A combined global-local approach. Journal of Cleaner Production, 140, 692-704. https://doi.org/10.1016/j.jclepro.2016.07.022

Rodrigues, G. S., Rodrigues, I. A., Buschinelli, C. C. de A., \& De Barros, I. (2010). Integrated farm sustainability assessment for the environmental management of rural activities. Environmental Impact Assessment Review, 30(4), 229-239. https://doi.org/10.1016/j.eiar.2009.10.002

Rosano Peña, C., Serrano, A. L. M., De Britto, P. A. P., Franco, V. R., Guarnieri, P., \& Thomé, K. M. (2018). Environmental preservation costs and eco-efficiency in Amazonian agriculture: Application of hyperbolic distance functions. Journal of Cleaner Production, 197, 699-707. https://doi.org/10.1016/j.jclepro.2018. 06.227

Sanjuan, N., Ribal, J., Clemente, G., \& Fenollosa, M. L. (2011). Measuring and Improving Eco-efficiency Using Data Envelopment Analysis: A Case Study of Mahón-Menorca Cheese. Journal of Industrial Ecology, 15(4), 614-628. https://doi.org/10.1111/j.1530-9290.2011.00347.x

Schmidheiny, S. (1992). Changing course: A global business perspective on development and the environment. MIT Press.

SEEG (Sistema de Estimativa de Emissão de Gases). (2017). Dados de emissão de gases de efeito estufa no Brasil. Retrieved from http://seeg.eco.br

Shorthall, O. K., \& Barnes, A. P. (2013). Greenhouse gas emissions and the technical efficiency of dairy farmers. Ecological Indicators, 29, 478-488. https://doi.org/10.1016/j.ecolind.2013.01.022

Spellerberg, I. A. N. F., \& Fedor, P. J. (2003). A Tribute to Claude Shannon (1916-2001) and a Plea for More Rigorous Use of Species Richness. Global Ecology and Biogeography, 12(3), 177-179. https://doi.org/ 10.1046/j.1466-822X.2003.00015.x

Tendall, D. M., \& Gaillard, G. (2015). Environmental consequences of adaptation to climate change in Swiss agriculture: An analysis at farm level. Agricultural Systems, 132, 40-51. https://doi.org/10.1016/j.agsy. 2014.09.006 
Todorovic, M., Mehmeti, A., \& Scardigno, A. (2016). Eco-efficiency of agricultural water systems: Methodological approach and assessment at meso-level scale. Journal of Environmental Management, 165, 62-71. https://doi.org/10.1016/j.jenvman.2015.09.011

Turral, H., Burke, J., \& Faurès, J.-M. (2011). Climate change, water and food security. FAO Water Reports 36. Food and Agriculture Organization of the United States (FAO), Rome.

United Nations Population Division. (2017). World Population Prospects 2017. https://population.un.org/wpp

Vlontzos, G., \& Pardalos, P. M. (2017). Assess and prognosticate green-house gas emissions from agricultural production of EU countries, by implementing, DEA Window analysis and artificial neural networks. Renewable and Sustainable Energy Reviews, 76(December 2016), 155-162. https://doi.org/10.1016/j.rser. 2017.03.054

Wang, C., Li, X., Gong, T., \& Zhang, H. (2014). Life cycle assessment of wheat-maize rotation system emphasizing high crop yield and high resource use efficiency in Quzhou County. Journal of Cleaner Production, 68, 56-63. https://doi.org/10.1016/j.jclepro.2014.01.018

Wang, S. L., Heisey, P., Schimmelpfennig, D., \& Ball, E. (2013). Agricultural Productivity Growth in the United States: Measurement, Drivers, and Impacts. Proceedings 59th ISI World Statistics Congress, Hong Kong (Session STS025). https://doi.org/10.22004/ag.econ.207954

World Bank. (2017). World Development Indicators. Retrieved from http://data.worldbank.org/data-catalog/ world-development-indicators

Xing, Z., Wang, J., \& Zhang, J. (2018). Expansion of environmental impact assessment for eco-efficiency evaluation of China's economic sectors: An economic input-output based frontier approach. Science of the Total Environment, 635, 284-293. https://doi.org/10.1016/j.scitotenv.2018.04.076

Zhou, S., Mueller, F., Burkhard, B., Cao, X., \& Hou, Y. (2013). Assessing Agricultural Sustainable Development Based on the DPSIR Approach: Case Study in Jiangsu, China. Journal of Integrative Agriculture, 12(7), 1292-1299. https://doi.org/10.1016/S2095-3119(13)60434-7

\section{Copyrights}

Copyright for this article is retained by the author(s), with first publication rights granted to the journal.

This is an open-access article distributed under the terms and conditions of the Creative Commons Attribution license (http://creativecommons.org/licenses/by/4.0/). 